shown to predict improvement in pain, pressure tenderness, fatigue, stiffness, depression, disturbed sleep, disease specific health, physical aspects and quality of life in persons with FM/CWP. There is lack of research about long-term follow-up of work status in FM and CWP. To enable patients with FM or CWP to sustain in work or return to work it is crucial to gain knowledge about which factors that can affect their work status in the long-term.

Objectives: To investigate change in work status and possible predictors of work status after 12 years in a cohort of women with FM and CWP.

Methods: In 2004, 166 women with FM and CWP participated in a randomized controlled trial in Sweden investigating effects of patient education and pool exercise. The 166 women were invited to participate in a follow-up study in 2016 in which long-term effects on work status, aspects of health and physical function were investigated. 126 participated in the follow-up study of which 98 were $<65$ years of age (age of retirement in Sweden) and included in the present study of work status. Data was collected by a standardized interview, a battery of questionnaires and an examination including tests of physical function. Work status refers to percentage of full-time work divided into four categories; $0 \% / 1-$ $49 \% / 50-79 \% / 80-100 \%$. Wilcoxon's signed-rank test was used for comparisons of work status over time within the group.

Multivariable forward stepwise logistic regression was used for analyses of predictors of work status after 12 years. The dependent variable was work status dichotomized into $<50 \% / \geq 50 \%$ work. Independent variables were baseline values of age, work status, symptoms of stress, pain intensity, overall health status, leisure time physical activity, walking capacity, health related quality of life and depression.

Results: The 98 women showed a significant increase in work status $(p<0.001)$ at the 12 years follow-up. Proportions of work status in category 1-4 at baseline were $56 \% / 10 \% / 22 \% / 10 \%$ and at follow-up it was $36 \% / 11 \% / 23 \% / 28 \%$. The participants' age, overall health assessed with Fibromyalgia Impact Questionnaire (FIQ) and health related quality of life assessed with SF-36 Physical component summary (PCS) at baseline predicted work status 10-12 years later. Age (years): OR 0.90 (95\% Cl 0.84-0.97), $\mathrm{p}=0.004$. FIQ total score (0-100): OR $0.94(95 \% \mathrm{Cl}$ $0.91-0.97), p<0.001$. SF-36 PCS (0-100): OR 1.1 (95\% Cl 1.0-1.2), $p=0.019$ Conclusions: Women with FM or CWP appear to improve their work status on group-level over time. Lower age, better overall health and higher health related quality of life at baseline were found to predict higher probability of working $50-100 \%$ after 12 years.

Disclosure of Interest: None declared

DOI: 10.1136/annrheumdis-2017-eular.4782

\section{THU0755-HPR DIETARY PROTEIN INTAKE AND UPPER LEG MUSCLE STRENGTH IN PATIENTS WITH KNEE OSTEOARTHRITIS: DATA FROM THE OSTEOARTHRITIS INITIATIVE}

A.H. de Zwart ${ }^{1}$, M. van der Leeden ${ }^{1,2}$, L.D. Roorda ${ }^{1}$, M. Visser ${ }^{3}$, M. van der Esch $^{1}$, W.F. Lems ${ }^{1,4,5}$, J. Dekker ${ }^{2,6} .{ }^{1}$ Amsterdam Rehabilitation Research Center, Reade; ${ }^{2}$ Dept of Rehabilitation Medicine, VU University Medical Center (VUmc); ${ }^{3}$ Dept. of Health Scienses, section Nutrition and Health, VU university Amsterdam; ${ }^{4}$ Dept of rheumatology, VU University Medical Center (VUmc); ${ }^{5} \mathrm{Jan}$ van Breemen Research Institute; ${ }^{6}$ Dept of Psychiatry, VU University Medical Center (VUmc), Amsterdam, Netherlands

Background: In patients with knee osteoarthritis (OA) muscle weakness is common and is strongly related to more pain and activity limitations. Therefore, conservative treatment focuses on optimizing muscle strength in patients with knee OA. Determinants of muscle strength such as muscle quantity and quality, level of pain and physical activity are widely studied in knee OA. Only a limited number of studies have focused on the relation between nutrition and muscle strength in patients knee OA.

Protein is an essential building block for muscle tissue. Adequate dietary protein intake is needed to preserve muscle tissue. In a part of the general older population lower intakes than the recommended daily protein intake are observed 1,2 . Higher levels of dietary protein intake have been linked to greater muscle mass and strength in older adults ${ }^{3,4}$. Whether there is an independent association between lower dietary protein intake and lower muscle strength in knee OA patients in unknown.

Objectives: To determine whether lower dietary protein intake is associated with lower muscle strength in patients with knee OA.

Methods: In this cross-sectional study, baseline data of patients with symptomatic and radiographic knee OA from the progression subcohort of the Osteoarthritis Initiative (OAl) were used. Protein intake was measured by the Block Brief 2000 food frequency questionnaire and expressed as g per day/ kg bodyweight. Knee muscle strength was measured in the index knee by the Good Strength chair test, and expressed as the sum of both flexion and extension strength ( $\mathrm{N} / \mathrm{kg}$ bodyweight). Linear regression analysis was used to test the association, adjusting for relevant demographic, clinical and behavioral confounders.

Results: Data from 1128 patients (mean age $61.7 \pm$ SD 9.1 y., $60.4 \%$ female) were used. A Kellgren and Lawrence grade of 2, 3 or 4 was scored in $25.7 \%$, $44.7 \%$ and $30.0 \%$ of the patients, respectively. The mean daily protein intake was $0.68 \pm$ SD $0.26 \mathrm{~g} / \mathrm{kg}$ bodyweight, and the mean muscle strength was 5.33 \pm SD 1.96 $\mathrm{N} / \mathrm{kg}$ bodyweight. In the unadjusted model, lower protein intake was associated with lower muscle strength $(B=-0.804,95 \% \mathrm{Cl}-0.336$ to $-1.272, p=0.001)$.
After adjusting for age and gender, lower protein intake was still associated with lower muscle strength $(B=-1.102,95 \% \mathrm{Cl}-0.680$ to $-1.524, \mathrm{p}<0.001)$ and was maintained after controlling for other relevant confounders.

Conclusions: Lower protein intake is independently associated with lower muscle strength in patients with knee OA. To confirm this relationship, future research is needed to test this association in longitudinal and interventional studies in patients with knee OA.

References:

[1] Fulgoni VL, 2008, Am J Clin Nutr 87:1554S-1557S.

[2] Kerstetter et al., $2003 \mathrm{~J}$ Nutr 133:855S-861S.

[3] Houston et al., 2008 Am J Clin Nutr. 2008 Jan; 87(1):150-5.

[4] Beasley et al., $2013 \mathrm{~J}$ Am Geriatr Soc. 2013;61(11):1863-71.

Disclosure of Interest: None declared

DOI: 10.1136/annrheumdis-2017-eular.3386

\section{THURSDAY, 15 JUNE 2017 \\ HPR patients' perspectives, functioning and health (descriptive: qualitative or quantitative)}

\section{THU0756-HPR PREDICTORS OF FEAR OF MOVEMENT IN PATIENTS WITH RHEUMATOID ARTHRITIS}

G.I. Kinikli ${ }^{1}$, H. Guney ${ }^{1}$, S. Karahan ${ }^{2}$, A. Ates ${ }^{3}$, M. Turgay ${ }^{3}$, G. Kinikli ${ }^{3}$.

${ }^{1}$ Department of Physiotherapy and Rehabilitation, Hacettepe University Faculty of Health Sciences; ${ }^{2}$ Department of Biostatistics, Hacettepe University Faculty of Medicine; ${ }^{3}$ Department of Rheumatology, Ankara University Faculty of Medicine, Ankara, Turkey

Background: Rheumatoid arthritis (RA) is a systemic chronic autoimmune inflammatory disease characterized by synovial joint inflammation that results in functional limitations accompanied by social and psychological outcomes.

Objectives: The aim of this study was to investigate the association between fear of movement and age, upper and lower extremity functions and functional disability in patients with Rheumatoid Arthritis (RA).

Methods: A total of 88 patients with RA participated to the study. Disease activity was assessed using the Disease Activity Score in 28 joints (DAS28). Functional disability was assessed using the Health Assessment QuestionnaireDisability Index (HAQ-DI). The Disabilities of the Arm, Shoulder and Hand Score (QuickDASH) was used to assess the upper extremity function. The Western Ontario and McMaster Universities Osteoarthritis Index (WOMAC) was used to assess the lower extremity function. The Tampa Scale for Kinesiophobia (TSK) was used to assess pain-related fear of movement. The multiple stepwise linear regression model with $R$-square $\left(R^{2}\right)$ was used to compare across the models and explain the total variance.

Results: Eight independent variables namely, age $(r=0.215 ; \mathrm{p}=0.044)$, QuickDASH $(r=0.504 ; p<0.001)$, HAQ-DI $(r=0.315 ; p=0.003)$, WOMAC Pain $(r=0.512$; $p<0.001)$, WOMAC Stiffness $(r=0.419 ; p<0.001)$, WOMAC Function $(r=0.398$; $p<0.001)$, WOMAC Total $(r=0.429 ; p<0.001)$, WOMAC range $(r=0.419 ; p<0.001)$, demonstrated significant correlations with TSK. There were correlations between two independent variables (QuickDASH, $\mathrm{p}=0.013$; WOMAC Pain, $\mathrm{p}=0.034$ ) and TSK $\left(R^{2}=0.293\right)$.

Conclusions: Health professionals should keep in mind that fear of movement were likely to cause poorer upper extremity functional disability and lower extremity pain levels in spite of varied drug therapies in patients with RA.

\section{References:}

[1] Wan, S. W., He, H.-G., Mak, A., Lahiri, M., Luo, N., Cheung, P. P., \& Wang, W. (2016). Health-related quality of life and its predictors among patients with rheumatoid arthritis. Applied Nursing Research, 30, 176-183.

[2] Doury-Panchout, F., Metivier, J., \& Fouquet, B. (2015). Kinesiophobia negatively influences recovery of joint function following total knee arthroplasty. European journal of physical and rehabilitation medicine, 51(2), 155-161.

Disclosure of Interest: None declared

DOI: 10.1136/annrheumdis-2017-eular.2817

\section{THU0757-HPR EUROPEAN QUALITATIVE RESEARCH PROJECT ON PATIENT-PREFERRED OUTCOMES IN EARLY RHEUMATOID ARTHRITIS (EQPERA): RATIONALE, DESIGN AND METHODS OF AN ONGOING MULTI-COUNTRY, MULTI-CENTER, MULTI-LANGUAGE, LONGITUDINAL QUALITATIVE STUDY}

K. Van der Elst ${ }^{1}$, A. Bremander ${ }^{2}$, A. De Groef ${ }^{1}$, I. Larsson ${ }^{3}$, E. Mathijssen ${ }^{4}$, J. Vriezekolk ${ }^{4}$, R. Westhovens ${ }^{1}$, Y. van Eijk-Hustings ${ }^{5} .{ }^{1}$ Rheumatology, University Hospitals Leuven, Leuven, Belgium; ${ }^{2}$ Research and Development Center; ${ }^{3}$ Spenshult Research and Development Center, Spenshult Hospital, Halmstad, Sweden; ${ }^{4}$ Department of Rheumatology, Sint-Maartenskliniek, Nijmegen; ${ }^{5}$ Department of Patient \& Care/Rheumatology, Maastricht University Medical Center, Maastricht, Netherlands

Background: Ample studies exist on outcome assessment from the patient perspective in Rheumatoid Arthritis (RA), but little is known about health and 
treatment preferences of recently diagnosed patients, and how these evolve over time. A Belgian qualitative study has set the scene (1), but knowledge on cross-cultural nuances in patient-preferred outcomes is lacking. To this end, EQPERA - European Qualitative research collaboration on Patient-preferred outcomes in Early Rheumatoid Arthritis- was founded.

Objectives: EQPERA aims to unravel longitudinally preferences for treatment and health outcomes among patients with early RA across Belgium, the Netherlands and Sweden. To yield sound results, specific preparations for this cross-country qualitative study are reported here.

Methods: Several steps have been undertaken to ensure trustworthiness of findings and consistency across countries in sampling, interviewing, analysis and project management: a detailed research protocol has been written; the interview guides have been translated following a structured forward-backward linguistic validation process; templates for data collection and a quality assurance reporting tool have been developed; and local staff has been trained and supervised by the project leader in implementing the study protocol. Each country will document changes with sufficient detail in their research logbook.

Results: EQPERA will be a qualitative, explorative, longitudinal study with active involvement of patient researchers. In each country, a purposive sample of patients with early RA will be individually interviewed 3-6 months after start of the initial RA treatment and subsequently, the same participants will be invited back to take part in a focus group 12-18 months after RA treatment initiation. Data collection and analysis will be independently conducted by the local research teams in their native language. The local teams will analyze their interview data using the constant comparison method as detailed in Qualitative analysis guide of Leuven, after which Saldana's guiding questions will be adopted for analyzing change over time. Afterwards, a meta-synthesis of all locally gathered and interpreted data will be conducted to explore and describe patterns, similarities and differences across countries.

Conclusions: This European project is a first step in gathering contextual findings on patient-preferred outcomes in early RA. Such knowledge is of crucial importance for tailoring therapeutic approaches in a timely and meaningful way. Our innovative, qualitative, longitudinal research design goes beyond the abilities of the frequently used cross-sectional designs in qualitative research. Large, multi-national qualitative projects are scarce in rheumatology research, thus applied data management and quality assurance strategies could be of interest to other researchers.

References:

[1] Van der Elst K, et al. Unraveling Patient-Preferred Health and Treatment Outcomes in Early Rheumatoid Arthritis: A Longitudinal Qualitative Study. Arthritis Care Res (Hoboken). Arthritis Care Res (Hoboken). 2016;68(9):127887.

Disclosure of Interest: None declared

DOI: 10.1136/annrheumdis-2017-eular.6747

\section{THURSDAY, 15 JUNE 2017 \\ HPR professional education, training and competencies}

\section{THU0758-HPR APPLICATION OF THE EULAR RECOMMENDATIONS FOR PATIENT EDUCATION FOR PEOPLE WITH INFLAMMATORY ARTHRITIS IN SWITZERLAND}

K. Niedermann ${ }^{1}$, C. Madelaine-Bonjour ${ }^{2}$, M. Roffler ${ }^{3}$, A. Kocher ${ }^{4}$ on behalf of Health Professionals in Rheumatology Switzerland. ${ }^{1}$ School of Health Professions, Zurich University of Applied Sciences, Winterthur; ${ }^{2}$ Rheumatology, University Hospital, Lausanne; ${ }^{3}$ Swiss League Against Rheumatism, Zurich; ${ }^{4}$ Rheumatology, University Hospital, Bern, Switzerland

Background: The recently published EULAR recommendations for patient education (PE) in people with inflammatory Arthritis (IA) encompass two overarching principles and eight recommendations (1). The average overall agreement of PE experts with the recommendations is usually high (at least 8.8 (SD+/-0.5) on a 1-10 Numeric Rating Scale NRS) $(1,2)$. The recommendations ought to be disseminated and implemented to establish a core standard for delivering PE and training for health professionals (HPs) in delivering PE across Europe.

Objectives: The Swiss HPs in rheumatology organisation, hpr Switzerland, aimed to evaluate the current standard of PE as well as the agreement with and application of the EULAR PE recommendations in Switzerland, in order to develop further implementation steps.

Methods: An online survey was conducted among HPs and rheumatologists in the major rheumatology clinics $(n=28)$ of the German and French part in Switzerland. The current knowledge and skills in PE and the performance of PE in clinical practice were assessed by multiple choice questions. The agreement with the PE recommendations was assessed on a 1-10 NRS and their application in the rheumatology clinics on a 4-point scale ("applied"/"rather applied"/"rather not applied"/"not applied").

Results: A total of $57 \mathrm{HPs}$, among them 12 rheumatologists, 21 nurses, 15 physiotherapists, 6 occupational therapists, 2 medical assistants) from 12 rheumatology clinics participated. Of these HPs, $31(55 \%)$ worked for more than
6 years in rheumatology and $15(27 \%)$ indicated to have a formal training in PE. They perceived that PE formed a substantial part of their work $(33.5 \%$ on average), the most important element being "providing information" $(48 \%)$, compared to $27 \%$ counselling and $25 \%$ behavioural interventions.

The average overall agreement with the PE recommendations was 7.0 (SD+/2.25). Recommendations 3 and 7 were well applied (72\%) in the rheumatology clinics. Least applied were the recommendations 4 and 6 with $21 \%$ and $24 \%$ respectively. Recommendations 1, 2, 5 and 8 reached between $40-50 \%$ application rates.

Image/graph shows Agreement with and Application of the PE Recommendations in Switzerland

Overarching principles

1. Patient education is a planned interactive learning process designed to support and enable people to manage their life with inflammatory arthritis and optimise their health and well being

2. Communication and shared decision making between people with inflammatory arthritis and their health care professionals are essential for effective patient education

\begin{tabular}{|c|c|c|c|}
\hline \multicolumn{2}{|c|}{ Recommendations } & \multirow{2}{*}{$\begin{array}{l}\begin{array}{c}\text { Agreement } \\
\text { mean (SD) }\end{array} \\
7.03(2.39)\end{array}$} & \multirow{2}{*}{$\begin{array}{c}\text { Application } \\
\text { '(rather) applied') } \\
42.4 \%\end{array}$} \\
\hline & $\begin{array}{l}\text { PE should be provided for people with IA as an integral part } \\
\text { of standard care in order to increase patient involvement in } \\
\text { disease management and health promotion }\end{array}$ & & \\
\hline 2. & $\begin{array}{l}\text { All people with IA should have access to and be offered PE } \\
\text { throughout the course of their disease including as a } \\
\text { minimum; at diagnosis, at pharmacological treatment } \\
\text { change and when required by the patient's physical or } \\
\text { psychological condition }\end{array}$ & $6.79(2.22)$ & $48.5 \%$ \\
\hline 3. & $\begin{array}{l}\text { The content and delivery of PE should be individually } \\
\text { tailored and needs-based for people with IA }\end{array}$ & $6.68(2.35)$ & $72.7 \%$ \\
\hline 4. & $\begin{array}{l}\text { PE in IA should include individual and/or group sessions, } \\
\text { which can be provided through face-to-face or online } \\
\text { interactions, and supplemented by phone calls, written or } \\
\text { multimedia material }\end{array}$ & $7.08(2.08)$ & $21.2 \%$ \\
\hline 5. & $\begin{array}{l}\text { PE programmes in IA should have a theoretical framework } \\
\text { and be evidence-based, such as self-management, cognitive } \\
\text { behavioural therapy, or stress-management }\end{array}$ & $7.08(2.20)$ & $48.5 \%$ \\
\hline 6. & $\begin{array}{l}\text { The effectiveness of PE in IA should be evaluated and } \\
\text { outcomes used must reflect the objectives of the PE } \\
\text { programme }\end{array}$ & $7.05(2.44)$ & $24.2 \%$ \\
\hline 7. & $\begin{array}{l}\text { PE in IA should be delivered by competent HPs and/or by } \\
\text { trained patients, if appropriate, in a multidisciplinary team }\end{array}$ & $7.26(2.26)$ & $72.7 \%$ \\
\hline 8. & $\begin{array}{l}\text { Providers of PE in IA should have access to and undertake } \\
\text { specific training in order to obtain and maintain knowledge } \\
\text { and skills }\end{array}$ & $6.82(2.08)$ & $42.3 \%$ \\
\hline
\end{tabular}

Conclusions: The overall agreement with the recommendations was high, although lower than the overall agreement of PE experts $(1,2)$. The application of most recommendations was found to be moderate to low in Swiss rheumatology institutions; however no comparisons with other countries are available. "Providing information" was reported as the most important PE element. This emphasises the need to implement the PE recommendations as well as to improve HPs' knowledge on delivering and evaluating effective $P E$, in order to provide beneficial PE interventions for people with IA in Switzerland.

References:

[1] Zangi, HA.; Ndosi, M; Adams, J; Andersen, L; Bode, C; Boström, C; van EijkHustings, Y; Gossec, L; Korandová, J; Mendes, G; Niedermann K; Primdahl, J; Stoffer, M; Voshaar, M; van Tubergen, A, (2015). EULAR recommendations for patient education for people with inflammatory arthritis. Ann Rheum Dis, 6 , 74. 954-62.

[2] Patermann J, Ehlebracht-König I, Lind-Albrecht G, Genth E, Reusch A, Küffner R, Müller-Ladner U, Braun J. EULAR recommendations for patient education of people with inflammatory arthritis. Translation and evaluation in Germany. Z Rheumatol. 2016 Mar;75(2):187-99.

Disclosure of Interest: None declared

DOI: 10.1136/annrheumdis-2017-eular.6038

\section{THURSDAY, 15 JUNE 2017}

HPR interventions (educational, physical, social and psychological)

\section{THU0759-HPR DOES PHYSIOTHERAPY AND REHABILITATION PROGRAM IMPROVE MOBILITY AND DAILY LIVING ACTIVITIES IN ELDERLY INPATIENT WITH OSTEOPOROSIS?}

M. Karapinar ${ }^{1}$, T. Firat ${ }^{2}$, N. Kirdi ${ }^{2} .{ }^{1}$ Department of Physiotherapy and Rehabilitation; ${ }^{2}$ Hacettepe University, Ankara, Turkey

Background: Osteoporosis (OP) is a generalized skeletal disorder characterized by compromised bone strength and deterioration of bone quality, often leading to fragility. Elderly osteoporosis is being public health problem that highly affects people especially above 65 years. Physiotheraphy and rehabilitation programs are 